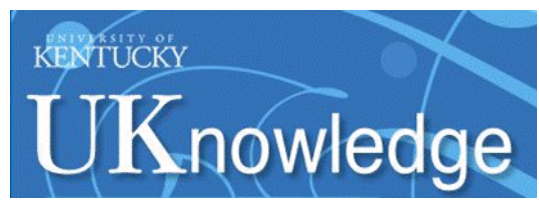

University of Kentucky

UKnowledge

5-1-2017

\title{
A Pilot Investigation of Acute Inhibitory Control Training in Cocaine Users
}

Joseph L. Alcorn

University of Kentucky, joseph.alcorn@uky.edu

Erika Pike

University of Kentucky, erika.pike@uky.edu

William W. Stoops

University of Kentucky,wwstoo0@email.uky.edu

Joshua A. Lile

University of Kentucky, jalile2@uky.edu

Craig R. Rush

University of Kentucky, crush2@uky.edu

Follow this and additional works at: https://uknowledge.uky.edu/behavsci_facpub

Part of the Behavior and Behavior Mechanisms Commons, Chemicals and Drugs Commons, and the Substance Abuse and Addiction Commons

Right click to open a feedback form in a new tab to let us know how this document benefits you.

\section{Repository Citation}

Alcorn, Joseph L.; Pike, Erika; Stoops, William W.; Lile, Joshua A.; and Rush, Craig R., "A Pilot Investigation of Acute Inhibitory Control Training in Cocaine Users" (2017). Behavioral Science Faculty Publications. 36. https://uknowledge.uky.edu/behavsci_facpub/36

This Article is brought to you for free and open access by the Behavioral Science at UKnowledge. It has been accepted for inclusion in Behavioral Science Faculty Publications by an authorized administrator of UKnowledge. For more information, please contact UKnowledge@lsv.uky.edu. 
A Pilot Investigation of Acute Inhibitory Control Training in Cocaine Users

Digital Object Identifier (DOI)

https://doi.org/10.1016/j.drugalcdep.2017.01.014

Notes/Citation Information

Published in Drug and Alcohol Dependence, v. 174, p. 145-149.

(c) 2017 Elsevier B.V. All rights reserved.

This manuscript version is made available under the CC-BY-NC-ND 4.0 license

https://creativecommons.org/licenses/by-nc-nd/4.0/.

The document available for download is the author's post-peer-review final draft of the article.

This article is available at UKnowledge: https://uknowledge.uky.edu/behavsci_facpub/36 
Drug Alcohol Depend. 2017 May 01; 174: 145-149. doi:10.1016/j.drugalcdep.2017.01.014.

\title{
A pilot investigation of acute inhibitory control training in cocaine users
}

\author{
Joseph L. Alcorn III ${ }^{1}$, Erika Pike ${ }^{1,2}$, William S. Stoops ${ }^{1,2,3}$, Joshua A. Lile ${ }^{1,2,3}$, and Craig R. \\ Rush $^{1,2,3}$ \\ ${ }^{1}$ Department of Behavioral Science, University of Kentucky College of Medicine, 1110 Veterans \\ Drive, Medical Behavioral Science Building Room 140, Lexington KY, 40536-0086, U.S.A \\ ${ }^{2}$ Department of Psychology, University of Kentucky College of Arts and Sciences, 110 Kastle Hall, \\ Lexington, KY, 40506-0044, U.S.A \\ ${ }^{3}$ Department of Psychiatry, University of Kentucky College of Medicine, 245 Fountain Court, \\ Lexington, KY, 40509-1810, U.S.A
}

\begin{abstract}
Background-Disrupted response inhibition and presence of drug-cue attentional bias in cocaine-using individuals have predicted poor treatment outcomes. Inhibitory control training could help improve treatment outcomes by strengthening cognitive control. This pilot study assessed the effects of acute inhibitory control training to drug- and non-drug-related cues on response inhibition performance and cocaine-cue attentional bias in cocaine-using individuals.

Methods-Participants who met criteria for a cocaine-use disorder underwent five sessions of inhibitory control training to either non-drug-related cues (i.e., rectangles) or cocaine cues ( $\mathrm{n}=10$ / condition) in a single day. Response inhibition and attentional bias were assessed prior to and following training using the stop-signal task and visual-probe task with eye tracking, respectively.
\end{abstract}

Correspondence concerning this article should be addressed to: Craig R. Rush, Ph.D., Department of Behavioral Science, University of Kentucky College of Medicine, 1110 Veterans Drive, Medical Behavioral Science Building Room 140, Lexington, KY, 40536-0086. Craig.Rush@uky.edu. Telephone: +1 (859) 323-5388. Facsimile: +1 (859) 257-7684.

Author Disclosure Statements

Role of funding source

This work was supported by grant numbers T32DA035200, R01DA025032, R01DA032254, R01DA033394, R21DA035481, R01DA036827 (PI: CRR), R21DA034095, R21DA035376, R01DA036553 (PI: WWS), R01DA033364 (PI: JAL) from the National Institute on Drug Abuse. These funding sources had no role in study design, data collection or analysis, or preparation and submission of the manuscript.

Contributors

J.L. Alcorn III and C.R. Rush developed the study concept and design. J.L. Alcorn III collected the data. E. Pike designed the inhibitory control training tasks. J.L. Alcorn III and E. Pike performed the data analysis and interpretation under the guidance of W.W. Stoops, J.A. Lile, and C.R. Rush, J.L. Alcorn III drafted the initial manuscript and all authors provided critical reviews and editing. All authors approved the final version of the manuscript for submission.

Conflict of interest

The authors have no financial conflicts of interest in regard to this research.

Publisher's Disclaimer: This is a PDF file of an unedited manuscript that has been accepted for publication. As a service to our customers we are providing this early version of the manuscript. The manuscript will undergo copyediting, typesetting, and review of the resulting proof before it is published in its final citable form. Please note that during the production process errors may be discovered which could affect the content, and all legal disclaimers that apply to the journal pertain. 
Results-Training condition groups did not differ on demographics, inhibitory control training performance, response inhibition, or cocaine-cue attentional bias. Response inhibition performance improved as a function of inhibitory control training in both conditions. Cocaine-cue attentional bias was observed, but did not change as a function of inhibitory control training in either condition.

Conclusions-Response inhibition in cocaine-using individuals was augmented by acute inhibitory control training, which may improve treatment outcomes through better behavioral inhibition. Future studies should investigate longer-term implementation of inhibitory control training, as well as combining inhibitory control training with other treatment modalities.

\section{Keywords}

Inhibitory control training; response inhibition; attentional bias; cocaine-use disorders

\section{Introduction}

Effective inhibition of motivated behaviors triggered by external cues is critical for accomplishing adaptive behavior change (Verbruggen et al., 2014). There has been recent interest in developing interventions that improve inhibitory control in individuals with substance use disorder (Sofuoglu et al., 2013). Cocaine-using individuals display disrupted response inhibition (Fillmore and Rush, 2002; Lane et al., 2007; Verdejo-García et al., 2007; Verdejo-García and Pérez-García, 2007) and cocaine-cue attentional bias (Hester et al., 2006; Lui et al., 2011; Marks et al., 2014a; 2014b; Vadhan et al., 2007). These deficits have been associated with poor treatment retention (Carpenter et al., 2006; Marhe et al., 2013; Streeter et al., 2008; Verdejo-García et al., 2012; Waters et al., 2012).

Poor inhibitory performance is worsened following the presentation of cocaine cues in cocaine users, as demonstrated by inhibitory failures on the Attentional Bias-Behavioral Activation (ABBA) task (Pike et al., 2013, 2015). This cue-dependent response suggests that disproportionate attention towards cocaine cues interacts with cognitive-control mechanisms to exacerbate impaired inhibitory control. Prior research has demonstrated that inhibitory control training involving repeated associative pairings between salient cues and successful inhibition is effective at engendering significant behavior change related to problematic alcohol (Houben et al., 2011, 2012; Jones and Field, 2013) and food (Houben and Jansen, $2011,2015)$ consumption. Inhibitory control training to cocaine cues might also be a useful therapeutic adjunct for problematic cocaine use, but this approach has not yet been evaluated.

The purpose of this pilot study was to test the effect of acute (i.e., one day) inhibitory control training to cocaine cues and a non-drug-cue control condition on response inhibition and cocaine-cue attentional bias in individuals with cocaine use disorder. We predicted that cocaine users who completed acute inhibitory control training to cocaine cues would display improved performance on both of these outcomes. 


\section{Methods}

\subsection{Participants}

Twenty non-treatment seeking participants completed this study. Participants were primarily recruited through word of mouth and postings on community bulletin boards. Participants completed screening questionnaires on their physical and mental health history, measures of current psychological functioning, detailed drug use history questionnaires, and a computerized version of the Structured Clinical Interview for the Diagnostic and Statistical Manual of Mental Disorders-IV (SCID; Sevak et al., 2011). All participants reported using cocaine within the last month, provided a cocaine-positive urine sample during screening procedures, and met criteria for cocaine abuse or dependence on the SCID. Exclusion criteria were: 1) current prescription for a psychiatric medication or 2) presence of a major medical or psychiatric condition (e.g., schizophrenia). Participants were also excluded if they reported dependence on any drug that produce significant withdrawal symptoms during testing (e.g., opioids and benzodiazepines), as they were asked to abstain from drug use for 12 hours prior to testing. All participants provided informed consent prior to beginning the study and were paid for their participation. The University of Kentucky Institutional Review Board approved all procedures, recruitment methods, and the informed consent document.

\subsection{Procedure}

Participants were randomized to complete the inhibitory-control training task with either cocaine-related images or rectangles as cues. Urn randomization matched participants on sex, cocaine use in the past month ( $>15$ days used or not), and years of education ( $\geq 12$ years education or not). The study consisted of a practice day (total time approximately 1 hour) to familiarize participants with the computerized measures of response inhibition and cocainecue attentional bias, and one day of inhibitory control training (total time approximately 6 hour). Response inhibition and cocaine-cue attentional bias were assessed at two time-points on the day of inhibitory control training: pre-training and post-training (both occurring 45 minutes before and after training, respectively). All computerized tasks were administered using E-prime software (Psychology Software Tools, Pittsburgh, PA) on a PC computer.

\subsection{Computerized tasks}

2.3.1. Inhibitory control training task-Participants completed five sessions (each separated by 1 hour) of inhibitory control training to either cocaine images or rectangles as cues. In the cocaine condition, go cues were neutral images and no-go cues were cocainerelated images. In the neutral condition, go and no-go cues were vertical and horizontal rectangles, respectively. In both training conditions, the color green served as the go target and color blue served as the no-go target. Participants were instructed not to respond to any image or rectangle, but to only respond once the cue was replaced by a green rectangle (i.e., go target). The inhibitory control-training task used a similar procedure as the ABBA task (described in detail in Pike et al., 2013, 2015), except go and no-go cues always predicted go and no-go targets, respectively. Participants began with $\$ 1.65$ bonus earnings at the beginning of each training session. Five cents were deducted from this $\$ 1.65$ bonus for each error that occurred (commission errors on no-go trials and omission errors on go trials) during the training session. The dependent variables were the number of go targets (125 
total) to which participants correctly responded and the number of no-go targets (125 total) to which participants correctly withheld a response.

2.3.2. Stop-signal task-Response inhibition performance was measured as the failure to inhibit responses following stop-signals. Briefly, letters ( $\mathrm{X}$ or $\mathrm{O}$ ) were presented on a computer screen one at a time. Participants were instructed to identify the letter using a keyboard. The stop-signal (a $500 \mathrm{~ms} 900 \mathrm{~Hz}$ tone) occurred on approximately $30 \%$ of trials (50) and participants were instructed to withhold their response in the presence of this tone. The stop-signal was randomly presented after the onset of a letter $(\mathrm{X}$ or $\mathrm{O})$ at one of five delays $(10,70,150,230$, or $300 \mathrm{~ms})$ and was divided evenly between letters. The dependent variables from the stop-signal task were the mean proportion of inhibitory failures following the stop-signal and stop-signal reaction time (SSRT; the estimated time to inhibit responses to the stop-signal; Logan, 1994). This task was used as the primary outcome of inhibitory control to: (1) avoid contamination of acute inhibitory control training with a cued go-no go or ABBA task that is very similar to the training task (Pike et al., 2013, 2015; Weafer and Fillmore, 2012a, 2012b) and (2) examine whether acute inhibitory control training conferred benefits in response inhibition performance beyond impulsive responses to cocaine cues.

2.3.3. Visual-probe task-Attentional bias was measured as fixation time to the cocaine and neutral cues using a Tobii X2-60 eye tracker (Tobii Technology, Sweden; procedure described in detail in Marks et al., 2014a). The dependent variable from the visual-probe task was the mean fixation time (ms). Mean fixation time was calculated by summing the total fixation time for each cue type and then dividing by the total number of critical trials (i.e., 40). Two participants' data from the visual-probe task were removed because eyetracking data were insufficient (i.e., greater than 2 SDs below the mean number of fixations recorded). One additional participant's data from the visual-probe task were removed because the eye-tracker was not able to record the participant's eye movements.

\subsection{Data analysis}

Statistical analyses were performed in SPSS Version 22 (IBM Corporation, Armonk, NY) with an alpha level set at $p \leq 0.05$ for all outcomes. Independent-samples t-tests were conducted to compare demographics for each training condition (cocaine cues vs. rectangles) for continuous variables. Chi-square analyses were conducted to compare sex and ethnicity/race distribution. Behavioral performance outcomes from all tasks were analyzed using mixed-model ANOVAs with training condition as the between-subjects factor. Two ANOVAs were used for comparisons of accurate responding to go targets and accurate withholding to no-go targets on the training tasks, with trial number (i.e., 1-5) as the within-subjects factor. ANOVAs were conducted on both outcomes from the stop-signal task (proportion of inhibitory failures and SSRT) with time-point (i.e., pre- and posttraining) as the within-subject factor in both models. An ANOVA was also conducted on mean fixation time from the visual-probe task with cue type (cocaine vs. neutral) and timepoint (i.e., pre- and post-training) as the within-subjects factors. Post-hoc comparisons with Bonferroni's adjustment were conducted following the mixed-model ANOVAs if significant effects were found. Effect sizes for significant results were calculated as partial eta squared $\left(\eta_{p}^{2}\right)$. Observed power for significant results are reported. 


\section{Results}

\subsection{Sample characteristics}

There were no significant differences between the training groups on any demographic variable (Table 1).

\subsection{Computerized tasks}

3.2.1 Inhibitory control training task-No significant effects on correctly withheld responses or correctly executed responses were found between groups across all trials (all $F S$ $<2.25$, $p s>0.05$ ).

3.2.2. Stop-signal task-ANOVAs revealed significant main effects of time-point on the proportion of inhibitory failures following stop-signals $\left(F_{(1,18)}=4.62, p=0.05, \eta_{p}^{2}=0.20\right.$, power $=0.53$; Figure $1 \mathrm{~A})$ and on the $\operatorname{SSRT}\left(F_{(1,18)}=4.98, p=0.04, \eta_{p}^{2}=0.22\right.$, power $=$ 0.56 ; Figure $1 \mathrm{~B})$. Post-hoc comparisons revealed that the proportion of inhibitory failures and SSRT decreased after inhibitory control training for both conditions. No other significant effects were detected (all $F s<1.00, p s>0.05$ ).

3.2.3 Visual-probe task-A significant main effect of cue type $\left(F_{(1,15)}=8.36, p=0.01\right.$, $\eta_{p}^{2}=0.36$, power $=0.77$; Figure 1C) was detected for fixation time. Post-hoc comparisons revealed that the mean fixation time to cocaine cues was greater than neutral cues. No other significant effects were detected (all $F s<2.25, p s>0.05$ ).

\section{Discussion}

This pilot study was the first to examine acute inhibitory control training in cocaine-using individuals. This study also extended the previous literature by assessing changes in response inhibition outside of the training task (i.e., the stop signal task) and using a measure of cue-specific attentional bias (i.e., the visual probe with eye tracking), which have not been included in prior studies that examined the acute effect of inhibitory control training to alcohol cues in heavy drinkers.

Inhibition is a key component of executive control that is often impaired in substance-use disorder (Verbruggen and Logan, 2008, 2009). For example, Fillmore and Rush (2002) found that chronic cocaine users displayed greater proportions of inhibitory failures and longer SSRTs than non-cocaine-using controls on the stop-signal task, suggesting that impaired inhibitory control in cocaine-using individuals might be due to a generalized slowing of the processes that inhibit impulsive responses. Therefore, the reduced proportions of inhibitory failures and shortened SSRTs observed in cocaine-using individuals following acute inhibitory control training in this study are noteworthy and suggest that greater executive control over impulsive behavior resulted from acute training. These novel data are clinically meaningful because disinhibition in cocaine-using individuals has been associated with poor treatment retention (Streeter et al., 2008; Verdejo-García et al., 2012). Inhibitory control training might therefore promote improved treatment outcomes for individuals seeking treatment for their cocaine use, though future studies are needed to assess this possibility. 
The magnitude of cocaine-cue attentional bias in this study fell within the large effect size range for partial-eta squared $\left(\eta_{p}^{2}=0.36\right.$; Cohen, 1988), which is within the same effect size range as the reported Cohen's d values from previous studies that used this task (Cohen's ds: 1.2 - 1.9; Marks et al., 2014a, 2014b). Neither type of acute inhibitory control training altered attentional bias. There are two potential reasons for this null finding. First, there is no inhibitory-control component of the visual-probe task. The use of an antisaccade task to assess visual inhibitory control in cocaine-cue attentional bias would be needed to reveal an impact of inhibitory control training on attentional bias tracked by eye movements (Dias et al., 2015; DiGirolamo et al., 2015). Second, a single day of acute inhibitory control training is insufficient to offset the learned associations that contribute to cocaine-cue attentional bias. Attentional bias is theorized to develop from acquired motivational salience that occurs from repeated pairings of substance use with proximal environmental cues (Field and Cox, 2008). Behavioral Stimulus Interaction theory (Veling et al., 2008) posits that motivational stimuli, such as cocaine cues, are devalued through multiple pairings of the cues with successful behavioral inhibition. Cocaine-cue stimulus devaluation through successful inhibition may rely more on automatic processes that are more resistant to change, whereas response inhibition relies on executive processes that are more flexible (Wiers and Stacy, 2006; Wiers et al., 2007). Thus, extensive inhibitory control training sessions would be needed to diminish the associative strength of drug-cue pairings that contribute to cocainecue attentional bias.

Although the small sample size of this pilot investigation is a limitation, it is important to note that all statistically significant outcomes achieved appreciable power (range: 0.53 0.77). There are two additional study limitations that are worth mentioning. First, one day of five training sessions was delivered, and as noted above, this limited amount of training was insufficient to reduce cocaine-cue attentional bias. Future studies should investigate the efficacy of multiple sessions of inhibitory control training. Second, the present study did not assess cocaine use following training. An aim for future studies is to determine if inhibitory control training reduces cocaine use in the natural ecology and on self-administration procedures under controlled laboratory conditions.

This study contributed to our understanding of the impact of inhibitory control training in stimulant users by demonstrating that both neutral and cocaine-related training procedures augmented a clinically relevant behavior (i.e., response inhibition), but did not change attentional bias in cocaine users. Long-term implementation of inhibitory control training, possibly in conjunction with other behavioral interventions (e.g., cognitive-behavioral therapy or contingency management) or pharmacotherapeutics, could lead to adaptive behavior change and improved treatment outcomes.

\section{References}

Carpenter KM, Schreiber E, Church S, McDowell D. Drug Stroop performance: Relationships with primary substance of use and treatment outcome in a drug-dependent outpatient sample. Addict Behav. 2006; 31:174-181. [PubMed: 15913898]

Cohen, J. Statistical Power Analysis For The Behavioral Sciences. 2. Hillsdale, NJ: Erlbaum; 1988. 
Dias NR, Schmitz JM, Rathnayaka N, Red SD, Sereno AB, Moeller FG, Lane SD. Anti-saccade error rates as a measure of attentional bias in cocaine dependent subjects. Behav Brain Res. 2015; 292:493-499. [PubMed: 26164486]

DiGirolamo GJ, Smelson D, Guevremont N. Cue-induced craving in patients with cocaine use disorder predicts cognitive control deficits toward cocaine cues. Addict Behav. 2015; 47:86-90. [PubMed: 25900705]

Field M, Cox WM. Attentional bias in addictive behaviors: A review of its development, causes, and consequences. Drug Alcohol Depend. 2008; 97:1-20. [PubMed: 18479844]

Fillmore MT, Rush CR. Impaired inhibitory control of behavior in chronic cocaine users. Drug Alcohol Depend. 2002; 66:265-273. [PubMed: 12062461]

Hester R, Dixon V, Garavan H. A consistent attentional bias for drug-related material in active cocaine users across word and picture versions of the emotional stroop task. Drug Alcohol Depend. 2006; 81:251-257. [PubMed: 16095852]

Houben K, Jansen A. Training inhibitory control. A recipe for resisting sweet temptations. Appetite. 2011; 56:345-349. [PubMed: 21185896]

Houben K, Nederkoorn C, Wiers RW, Jansen A. Resisting temptation: Decreasing alcohol-related affect and drinking behavior by training response inhibition. Drug Alcohol Depend. 2011; 116:132136. [PubMed: 21288663]

Houben K, Havermans RC, Nederkoorn C, Jansen A. Beer à no-go: Learning to stop responding to alcohol cues reduces alcohol intake via reduced affective associations rather than increased response inhibition. Addiction. 2012; 107:1280-1287. [PubMed: 22296168]

Houben K, Jansen A. Chocolate equals stop. Chocolate-specific inhibition training reduces chocolate intake and go associations with chocolate. Appetite. 2015; 87:318-323. [PubMed: 25596041]

Jones A, Field M. The effects of cue-specific inhibition training on alcohol consumption in heavy social drinkers. Exp Clin Psychopharmacol. 2013; 21:8-16. [PubMed: 23181512]

Lane SD, Moeller FG, Steinberg JL, Buzby M, Kosten TR. Performance of cocaine dependent individuals and controls on a response inhibition task with varying levels of difficulty. Am J Drug Alcohol Abuse. 2007; 33:717-726. [PubMed: 17891664]

Logan, GD. On the ability to inhibit thought and action: A users' guide to the stop-signal paradigm. In: Dagenbach, D., Carr, TH., editors. Inhibitory Processes in Attention, Memory, and Language. Academic Press; San Diego, CA: 1994. p. 189-239.

Lui S, Lane SD, Schmitz JM, Walters AJ, Cunningham KA, Moeller FG. Relationship between attentional bias to cocaine-related stimuli and impulsivity in cocaine-dependent subjects. Am J Drug Alcohol Abuse. 2011; 35:117-122.

Marhe R, Luijten M, van de Wetering BJ, Smit M, Franken IH. Individual differences in anterior cingulate activation associated with attentional bias predict cocaine use after treatment. Neuropsychopharmacology. 2013; 38:1085-1093. [PubMed: 23303067]

Marks KR, Roberts W, Stoops WW, Pike E, Fillmore MT, Rush CR. Fixation time is a sensitive measure of cocaine cue attentional bias. Addiction. 2014a; 109:1501-1508. [PubMed: 24894879]

Marks KR, Pike E, Stoops WW, Rush CR. Test-retest reliability of eye tracking during the visual probe task in cocaine-using adults. Drug Alcohol Depend. 2014b; 145:235-237. [PubMed: 25456573]

Pike E, Stoops WW, Fillmore MT, Rush CR. Drug-related stimuli impair inhibitory control in cocaine abusers. Drug Alcohol Depend. 2013; 133:768-771. [PubMed: 24004904]

Pike E, Marks KR, Stoops WW, Rush CR. Cocaine-related stimuli impair inhibitory control in cocaine users following short stimulus onset asynchronies. Addiction. 2015; 110:1281-1286. [PubMed: 25873430]

Sevak RJ, Vansickel AR, Stoops WW, Glaser PE, Hays LR, Rush CR. Discriminative stimulus, subject-rated, and physiological effects of methamphetamine in humans pretreated with aripiprazole. J Clin Psychopharmacol. 2011; 31:470-480. [PubMed: 21694622]

Sofuoglu M, DeVito E, Waters AJ, Carroll KM. Cognitive enhancement as a treatment for drug addictions. Neuropharmacology. 2013; 64:452-463. [PubMed: 22735770]

Streeter CC, Terhune DB, Whitfield TH, Gruber S, Sarid-Segal O, Silveri MM, Tzilos G, Afshar M, Rouse ED, Tian H, Renshaw PF, Ciraulo DA, Yuraelun-Todd DA. Performance on the Stroop 
predicts treatment compliance in cocaine-dependent individuals. Neuropsychopharmacology. 2008; 33:827-836. [PubMed: 17568399]

Vadhan NP, Carpenter KM, Copersine ML, Hart CL, Foltin RW, Nunes EV. Attentional bias towards cocaine-related stimuli: relationship to treatment-seeking for cocaine dependence. Am J Drug Alcohol Abuse. 2007; 33:727-736. [PubMed: 17891665]

Veling H, Holland RW, van Knippenberg A. When approach motivation and behavioral inhibition collide: Behavior regulation through stimulus devaluation. J Exp Soc Psychol. 2008; 44:10131019.

Verbruggen F, Logan GD. Response inhibition in the stop-signal paradigm. Trends Cogn Sci. 2008; 12:418-424. [PubMed: 18799345]

Verbruggen F, Logan GD. Models of response inhibition in the stop-signal and stop-change paradigms. Neurosci Biobehav Rev. 2009; 33:647-661. [PubMed: 18822313]

Verbruggen F, Best M, Bowditch WA, Stevens T, McLaren IP. The inhibitory control reflex. Neuropsychologia. 2014; 65:263-278. [PubMed: 25149820]

Verdejo-García AJ, Perales JC, Pérez-García M. Cognitive impulsivity in cocaine and heroin polysubstance abusers. Addict Behav. 2007; 32:950-960. [PubMed: 16876962]

Verdejo-García A, Pérez-García M. Ecological assessment of executive functions in substance dependent individuals. Drug Alcohol Depend. 2007; 90:48-55. [PubMed: 17382487]

Verdejo-García A, Betanzos-Espinosa P, Lozano OM, Vergara-Moragues E, González-Saiz F, Fernández-Calderón F, Bilbao-Acedos I, Pérez-García M. Self-regulation and treatment retention in cocaine dependent individuals: A longitudinal study. Drug Alcohol Depend. 2012; 122:142148. [PubMed: 22018602]

Waters AJ, Marhe R, Franken IH. Attentional bias to drug cues is elevated before and during temptations to use heroin and cocaine. Psychopharmacology. 2012; 219:909-921. [PubMed: 21833505]

Weafer J, Fillmore MT. Alcohol-related stimuli reduce inhibitory control of behavior in drinkers. Psychopharmacology. 2012a; 222:489-498. [PubMed: 22358851]

Weafer J, Fillmore MT. Comparison of alcohol impairment of behavioral and attentional inhibition. Drug Alcohol Depend. 2012b; 126:176-182. [PubMed: 22673197]

Wiers RW, Stacy AW. Implicit cognition and addiction. Curr Dir Psychol Sci. 2006; 15:292-296.

Wiers RW, Bartholow BD, van den Wildenberg E, Thush C, Engels RC, Sher KJ, Grenard J, Ames SL, Stacy AW. Automatic and controlled processes and the development of addictive behaviors in adolescents: A review and a model. Pharmacol Biochem Behav. 2007; 86:263-283. [PubMed: 17116324]

Drug Alcohol Depend. Author manuscript; available in PMC 2018 May 01. 


\section{Highlights}

- Acute inhibitory control training tested in cocaine users

- Cocaine users were assigned to cocaine or neutral cue training

- Improved response inhibition performance was observed in both conditions

- $\quad$ Cocaine-cue attentional bias was not altered by acute inhibitory control training 

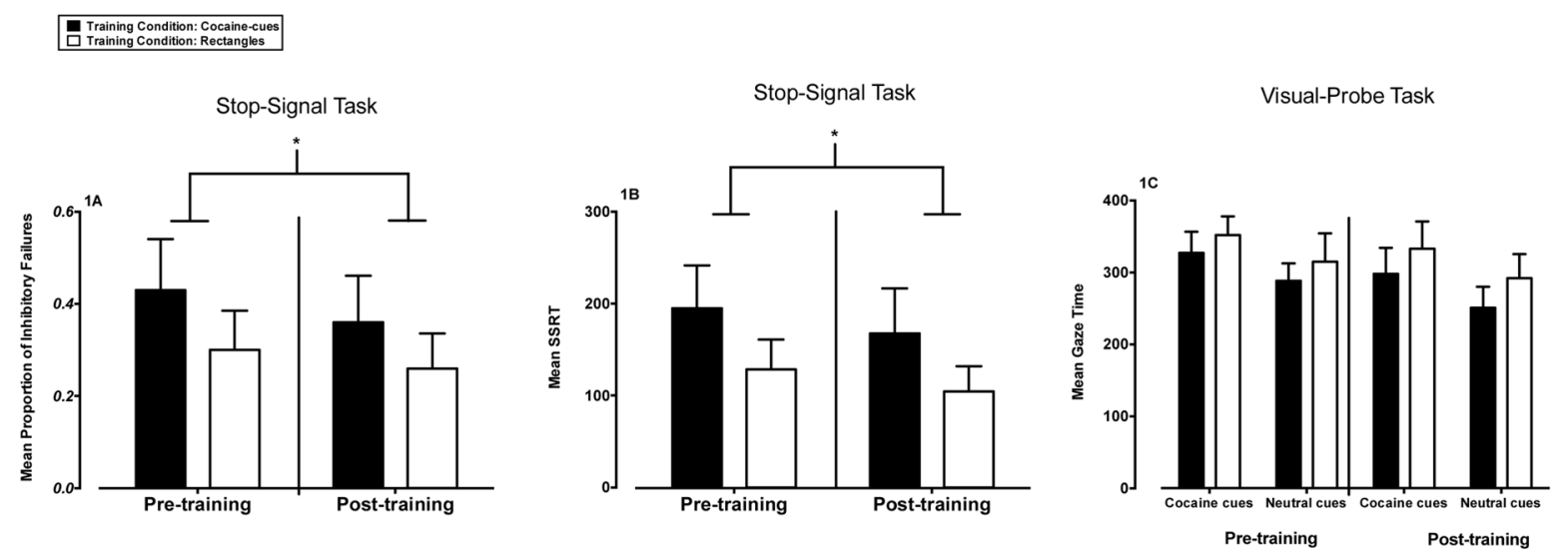

Figure 1.

Panel 1A: Mean proportion of inhibitory failures (+SEM) during stop trials on the stopsignal task as a function of inhibitory control training to cocaine-cues $(n=10)$ and rectangles $(n=10)$. Proportion of inhibitory failures means are shown for pre-training (left two bars) and post-training (right two bars). Reduced proportion of inhibitory failures represents improved performance.

Panel 1B: Mean SSRT (+SEM) to the stop-signal on the stop-signal task as a function of inhibitory control training to cocaine-cues $(n=10)$ and rectangles $(n=10)$. Mean SSRTs are shown for pre-training (left two bars) and post-training (right two bars). Lower SSRT represents faster executive control of inhibiting erroneous impulsive responses.

Panel 1C: Mean gaze time (ms; +SEM) from the visual-probe task as a function of inhibitory control training to cocaine-cues $(n=9)$ and rectangles $(n=8)$. Mean gaze times are shown for pre-training (left four bars) and post-training (right four bars). Attentional bias toward cocaine cues is shown by greater mean gaze time to cocaine cues than to neutral cues. $*=$ significant main effect of time-point $(p<0.05)$ 


\section{Table 1}

Participant demographics by training condition and group comparisons.

\begin{tabular}{|l|c|c|c|}
\hline \multicolumn{5}{|c|}{ Inhibitory Control Training Condition } \\
\hline Demographic variable & Cocaine-cues & Rectangles & t or $\chi^{2}$-Value \\
\hline Group size $(n):$ & 10 & 10 & - \\
\hline UDS+ for cocaine metabolites $(n):$ & 10 & 9 & - \\
\hline Sex (n male/female): & $6 / 4$ & $6 / 4$ & 0.00 \\
\hline Mean age $( \pm$ SEM): & $50.4(1.0)$ & $45.7(1.1)$ & 2.02 \\
\hline Mean years of education $( \pm$ SEM): & $11.7(0.5)$ & $12.3(0.5)$ & -0.90 \\
\hline Race/Ethnicity (n AA/C/MO): & $5 / 4 / 1$ & $8 / 2 / 0$ & 0.26 \\
\hline Mean cigarettes/day $( \pm$ SEM): & $9.2(2.1)$ & $10.1(2.5)$ & -0.26 \\
\hline Mean alcoholic drinks/week $( \pm$ SEM): & $18.8(8.3)$ & $16.4(7.9)$ & 0.22 \\
\hline Mean DAST score $( \pm$ SEM): & $10.2(1.8)$ & $11.4(1.9)$ & -0.47 \\
\hline Mean days of cocaine use $( \pm$ SEM) & & & \\
\hline -Past week: & $2.7(0.3)$ & $3.5(0.8)$ & -0.98 \\
\hline -Past month: & $12.6(1.5)$ & $13.3(3.1)$ & -0.21 \\
\hline
\end{tabular}

Note. UDS+ = positive urine drug screens on the day of inhibitory control training, AA = African-American; C = Caucasian; MO = Mixed/Other; DAST $=$ Drug Abuse Screening Test; SEM = standard error of the mean. 